\title{
Del Programa d'Educació Compensatòria al nou Pla per a la Llengua i la Cohesió Social
}

\section{Núria Llevot Calvet}

Doctora en Psicopedagogia. Universitat de Lleida

nllevot@pip.udl.es

\section{Resum}

El Programa d'Educació Compensatòria va ser el fruit emblemàtic de la política reformista empresa el 1983 en el camp pedagògic. Es tractava d'un discurs destinat a corregir les desigualtats socials i assolir quotes més elevades de justícia social. Actualment, en el context català ha estat considerat necessari un doble canvi, davant el ràpid increment de la població escolar procedent de la immigració i l'aparició de noves formes d'exclusió social: per una banda, una adequada integració educativa, social i cultural de tot l'alumnat independentment del seu origen i condició, i, per l'altra, la consolidació de la llengua catalana com a llengua vehicular de l'ensenyament i com a element de cohesió social en un marc plurilingüe.

Paraules clau: compensatòria, minories ètniques, escola, llengua i cohesió social.

Abstract. From the Compensatory Education Programme to the new Plan for Language and Social Cohesion

The Compensatory Education Programme was the emblematic result of the reformist policy adopted in 1983 in the field of education. It was a discourse aimed at correcting social inequalities and producing higher levels of social justice. Nowadays, in the Catalan context, a double change has been considered necessary, given the rapid increment in the immigrant-origin school population and the appearance of new forms of social exclusion. On one hand, this takes the form of adequate educational, social and cultural integration of all students independently of their origins and condition and, on the other, the consolidation of Catalan as a vehicular language in teaching and as an element of social cohesion in a multilingual framework.

Key words: compensatory, ethnic minorities, school, language and social cohesion.

\section{Sumari}

Introducció

Creació i desenvolupament del Programa d'Educació Compensatòria

El llarg procés d'evolució cap a una educació intercultural
La transformació al Pla per a la Llengua i la Cohesió Social (LIC)

A tall de reflexions obertes Referències bibliogràfiques 


\section{Introducció}

En aquest article, s'hi exposa bàsicament l'evolució que ha sofert el Programa d'Educació Compensatòria del Ministeri d'Educació espanyol, més concretament a Catalunya els canvis que ha tingut fins arribar a convertir-se en el Pla per a la Llengua i la Cohesió Social ${ }^{1}$. Aquest programa va ser el fruit emblemàtic de la política reformista empresa el 1983 en el camp pedagògic, es tractava, doncs, d'un discurs optimista i esperançat, destinat a corregir les desigualtats socials i assolir quotes més elevades de justícia social.

Malgrat les debilitats inherents d'aquest plantejament, el Programa de Compensatòria ha possibilitat intervencions reals en àmbits especialment complexos, i el ventall d'actuacions ha estat sempre molt ampli i ambiciós. Actualment, la seva desaparició i transformació en un altre pla presenta un dels reptes que encara té l'Administració catalana per atendre l'escolarització de les minories ètniques en risc de marginació sociocultural ${ }^{2}$.

\section{Creació i desenvolupament del Programa d'Educació Compensatòria}

A l'Estat espanyol, l'educació compensatòria s'hi inicia l'any 1983 (Reial Decret de 27 d'abril de 1983, BOE de l'11 de maig), amb la creació d'un programa específic que té l'objectiu prioritari de prestar una atenció pedagògica preferent en aquelles zones geogràfiques o grups de població que, per les seves característiques peculiars, ho requereixin. Les actuacions que principalment havia de realitzar el nou programa eren, entre d'altres (CIDE, 1992): la creació de serveis de reforç amb seu als centres de recursos ubicats en zones d'acció educativa preferents per a ajuda escolar; la incentivació de la continuïtat del professorat destinat a vacants de provisió difícil; l'organització de cursos de formació ocupacional per a joves no escolaritzats entre els catorze i els quinze anys; l'eradicació de l'analfabetisme i la creació de modalitats específiques per a l'estudi. En línies generals, el projecte espanyol, promulgat pel ministre Maravall del primer Govern socialista de Felipe González, estava directament inspirat en la controvertida experiència laborista de les Educational Priority Areas ${ }^{3}$.

1. Per confeccionar aquest treball, s'han utilitzat fonts documentals del Programa d'Educació Compensatòria (PEC) i del Departament d'Educació, també s'han realitzat entrevistes en profunditat al coordinador del Programa d'Educació Compensatòria de Catalunya, a la inspectora d'Educació que porta l'àmbit d'immigració a Lleida i a tots els membres de l'equip del PEC (mestres i treballadora social) de les comarques de Ponent.

2. Lobjectiu d'aquest treball era conèixer i valorar les actuacions i polítiques que s'han dut a terme per atendre les minories ètniques des del Departament d'Educació en els darrers anys.

3. Per L. Samper, N. Llevot, J. Garreta i M. H. Chastenay (2002), les polítiques educatives d'educació compensatòria, desenvolupades als Estats Units des del final de la dècada de 1950 i al Regne Unit durant els anys seixanta a partir de nocions com ara «deficiència cultural» (cultural deprivation) o "dèficit lingüístic» (lingü̈stic deprivation), aplicades, indistintament, a alumnes d'origen obrer o de minories ètniques, van ser qüestionades tant pels sectors d'opinió conservadora com per la nova sociologia de l'educació, vegeu Bernstein (1971). 
En un sentit ampli, Muñoz Sedano (1989) es refereix a la política educativa compensatòria, com ara les actuacions polítiques, econòmiques, socials i escolars de discriminació positiva aplicades a una població afectada per la pobresa econòmica, social i cultural, de forma que s'afavoreix la reducció i l'anul-lació dels desavantatges en el sistema educatiu. Durant el curs 1987-1988, es van desenvolupar a l'Estat espanyol un total de cinc programes ${ }^{4}$ dins del marc del programa global anteriorment mencionat, en què destacarem el Programa de Minories Culturals per la consideració del seu diferent sistema sociocultural i el desarrelament en què freqüentment es troben immersos, per aquesta raó qualsevol intent d'escolarització i reforç haurà de tenir sempre en compte les seves peculiaritats (nomadisme, alt grau de mobilitat d'aquests grups, etc.) (CIDE, 1992). A Catalunya, la circular del 15 de setembre de 1988, adreçada als centres que acollien alumnes en risc de marginació social, concretava l'existència del Programa de Marginats Socials d'Educació Compensatòria del Departament d'Ensenyament, que atendria els alumnes amb escolarització deficient ${ }^{5}$ motivada per (Departament d'Ensenyament, 1988):

- Matriculació tardana: infants que s'han escolaritzat per primera vegada amb més de set anys (o bé també amb més de cinc anys quan desconeixen totalment la llengua catalana i/o la castellana).

- Absentisme elevat: quan les absències de l'escola, motivades per nomadisme familiar o altres causes molt específiques, superin el nombre de cinquanta dies per curs escolar.

- Condicions de vida i de vivenda molt degradades: barris gueto, barraquisme, etc.

L’objectiu que es pretenia assolir era assegurar una escolarització tan normalitzada com fos possible, amb una integració adequada. Per ajudar a aconseguir-ho, el programa proporcionava suport educatiu amb professorat d'ensenyança general bàsica, recursos materials per a les aules i, si era possible, suport social a les famílies mitjançant l'actuació del treballador social i algunes ajudes que afavorien l'escolarització (generalment, menjador escolar, materials didàctics, sortides i convivències escolars). Quan es va crear el curs 1983-1984 (Jordán, 1992) — amb caràcter de provisionalitat i amb tres mestres en comissió de serveis-, atenia els nens gitanos del barri barceloní de La Perona i a poc a poc es va anar ampliant:

4. Els programes eren: Programa d'Atenció a l'Àrea Rural, de Projectes en Centres, d'Atenció a Joves Desescolaritzats, de Minories Culturals i de Població Itinerant (CIDE, 1992).

5. Concepte que inclou els alumnes en risc de marginació que presentin problemes de maduració personal, d'habituació i de socialització, com també dificultats relacionades amb la motivació i la continuïtat en l'aprenentatge degudes a la seva situació sociocultural. En canvi, s'escapen totalment de l'àmbit del Programa de Marginats Socials els estudiants amb dificultats d'educació especial, caracterials, amb mal comportament, absentisme motivat per problemes aliens a la marginació, etc. 
Més tard, el seu radi d'acció s'ha anat estenent a unes altres àrees de Barcelona capital (Raval, Ciutat Vella...), a altres ciutats de la província (Santa Coloma de Gramenet, Sant Adrià del Besòs, Santa Perpètua de Mogoda, Sabadell, Cerdanyola del Vallès, etc.), a Tarragona (Reus, Tortosa...) i Girona (Figueres, etc.). (Jordán, 1992, p. 174-175)

Uns quants anys més tard, el 19 de desembre de 1990, Javier Solana, llavors ministre del MEC, conjuntament amb Josep Laporte, conseller del Departament d'Ensenyament, van signar un conveni de col-laboració respecte a l'educació compensatòria, en el qual el Departament assumia l'execució de les actuacions a Catalunya. Lobjectiu principal del Programa de Marginats Socials d'Educació Compensatòria (Montano, Castella i Pérez, 1992) era donar ajuda per a la plena integració escolar de l'alumnat amb problemes de marginació social, ja fos per raons econòmiques, culturals i/o ètniques.

Les problemàtiques principals per a la integració d'aquest alumnat —fonamentalment gitano i àrab- (Benestar Social, 1994), detectades pel programa per mitjà de la informació i la col-laboració dels tutors i dels mestres, serviren per oferir solucions concretades en dos nivells (Programa d'Educació Compensatòria Tarragona/Lleida, 1994) i que sintetitzem en la taula posterior.

Totes aquestes necessitats es van concretar en una sèrie d'orientacions i d'actuacions (Departament d'Ensenyament, 1996b) que es van elaborar per al conjunt de mestres i treballadors socials del Programa d'Educació Compensatòria (PEC) de la Generalitat:

- Respecte a les orientacions per als centres davant l'escolarització de nens en risc: bases per a una integració adient, recomanacions per a la matriculació i adscripció al curs, documentació acadèmica per a la matriculació i convalidació pertinent, contacte i acollida de les famílies, suggeriments per a l'entrada del nen a l'aula, relacions amb el grup classe, facilitació d'una llista de material i recursos per tenir a l'aula. En el cas dels nens àrabs, esbrinar el nivell de competència lingüística de l'alumne, indicacions per a l'ensenyament de la llengua d'aprenentatge i prevenció de les principals dificultats afegides (a l'hora d'iniciar la lectoescriptura: la lateralitat, la direccionalitat, el grafisme...), així com respecte i comprensió vers la seva cultura. - Referent a les actuacions o línies de treball dels professionals: assessorar els centres on s'escolaritzen aquests alumnes, elaborar materials didàctics adaptats a les necessitats que presenten, l'oferta d'elements d'informació i formació dels tutors i mestres que els atenen, vetllar i prevenir situacions d'absentisme i abandonament escolar, garantir aquelles ajudes econòmiques (llibres, menjador...) que afavoreixen l'assistència assídua a classe i el seguiment dels alumnes.

Aquest programa, després de fer durant un temps els primers auxilis als centres, havia de reorientar la seva feina; en primer lloc, perquè ningú no pot suplir l'evident manca de recursos (materials, humans i organitzatius) que presenten els centres i, en segon lloc, perquè no serveixen actuacions marginals 
Taula 1. Problemàtiques per a la integració de l'alumnat de minories ètniques

\section{Amb relació als infants}

\section{Col-lectiu àrab Col-lectiu gitano}

- Desconeixement de les llengües d'aprenentatge.

- Desfasament entre el domini de la llengua comunicativa i la llengua d'aprenentatge.

- No coincidència del nivell d'aprenentatge escolar i el nivell maduratiu real de l'alumne.

— Limitacions en la relació entre la família i l'escola.

- Famílies amb nivells econòmics i condicions de vida en el marc de la marginació, no gaire diferents del nivell social de la resta de famílies de l'escola a vegades, però quasi sempre un esglaó per sota pel fet de ser immigrants.

- Xoc cultural 6 .

- Entrebanc per tramitar la documenta-

- Actituds i expectatives diferents respecte a la institució escolar.

- Manca d'hàbits socials (ordre, neteja, puntualitat, etc.), que constitueix un obstacle per a la integració en les escoles ordinàries.

- Cultura basada en la tradició oral.

- Desconeixement del català.

- Absentisme sistemàtic per anar a fer feines esporàdiques (per realitzar treballs que ajudin a resoldre l'economia familiar o atendre i cuidar els germans més petits) ${ }^{7}$.

- Desescolarització als onze o dotze anys (cultural).

— Escolarització tardana (a partir dels set anys).

— Percentatge elevat de fracàs escolar. ció acadèmica per la mateixa rèmora d'obtenir la del país d'origen.

- Interferències lingüístiques.

- Problemes de lateralitat.

\section{Amb relació a les institucions escolars}

- Acceptació o rebuig d'aquests estudiants a l'escola i a la diversitat en general.

- Impediments per fer efectiva l'atenció individualitzada que requereixen (almenys en els primers cursos), tant per no disposar de prou recursos humans com per no tenir-ne de tipus organitzatiu per fer un replantejament general de la institució.

— Necessitat d'establir coordinació entre l'escola —assistència social— i la família que vagi més enllà del simple tràmit econòmic.

- Manca de formació i d'assessorament del professorat per abordar la diversitat en el centre, tant en aspectes metodològics com de sensibilització i d'informació cultural.

6. «Els principals conflictes que sorgeixen a causa de la presència de treballadors estrangers procedents de països de l'anomenat “Tercer Món” no són deguts tant a una diversitat entre les personalitats individuals d'un ciutadà estranger i d'un d'autòcton —ni tampoc a les manifestacions del xoc intercultural entre les identificacions dels seus membres - com a uns determinats elements de les respectives cultures que entren en conflicte, mentre que la resta són majoritàriament acceptats sense gaires dificultats» (Carbonell, 1997, p. 83-84).

7. Es pot ampliar aquesta informació al Secretariado Nacional Gitano (1982). 
des de fora si les institucions no canvien, així com si tampoc ho fan les persones que les formen (amb les actituds, les avaluacions, etc.). De fet, durant el curs 1993-1994 va haver-hi una reestructuració, no exempta de tensions, divisions i dificultats, que va fer trontollar seriosament la continuïtat del programa, la qual cosa va provocar la fugida d'una part considerable dels membres cap a les seves destinacions definitives ${ }^{8}$. Exemple d'això va ser l'abandonament del propi creador i coordinador del programa per diferències amb la directora general quant a orientació de les línies de treball, com ens ho explica en una entrevista, on relata l'inici d'aquest:

Des del Departament d'Ensenyament, el director general que hi havia aleshores, en (nom i cognom de persona), que va morir l'any passat, em va demanar que em posés al capdavant del Programa d'Educació Compensatòria. Aquest programa va néixer per ajudar les escoles que agafaven població gitana. També va coincidir que les escoles del Camp de la Bota o de La Perona van desaparèixer, per aquest motiu, els alumnes gitanos van anar a les escoles ordinàries. Aleshores, el programa es deia Integració per intentar que no hi hagués guetos gitanos i aleshores el Programa d'Educació Compensatòria va començar per ajudar aquestes escoles on hi havia per primer cop alumnes gitanos i per ajudar els gitanos també a adaptar-se d'una escola només gitana a una escola, doncs, paia, una escola de barreja [...] El sisè any, amb la nova directora general, la (nom de persona), ja no vam compartir els criteris. La directora era partidària que el Programa d'Educació Compensatòria pràcticament es fusionés amb els EAP i va començar a sortir, doncs, aquesta idea que encara potser es té malauradament que els alumnes [...] són diferents gitanos i immigrants, però són alumnes amb problemes de necessitats educatives especials $i$, per tant, doncs els EAP ja servien, no? i, per tant, volia, doncs, que a més de compensatòria estiguessin adscrits als EAP. Com que no hi estava d'acord, això va provocar que, aquest final de curs, ho deixés [...].

\section{El llarg procés d'evolució cap a una educació intercultural}

A mesura que va passant el temps, els responsables del PEC han anat modificant la seva orientació i és evident que el discurs oficial sempre ha estat en «fase d'elaboració». La seva aplicació responia a diferents nivells (Palaudàrias, 1998): escola (actuacions directes i aportacions de materials), tutors (formació $\mathrm{i}$ informació per afrontar les problemàtiques que es presenten a l'aula), claustre (sessions per promoure un clima d'acceptació amb les singularitats de l'alumnat), actuacions per zones (de forma conjunta amb altres serveis i programes educatius, així com també amb els serveis socials), adaptació de continguts i de materials (modificant els continguts curriculars o adaptant-ne d'altres) i formació permanent del professorat (oferta de cursos per mitjà del Pla de Formació del Departament sobre sensibilització i iniciació en aquests temes). 
El programa també ha participat en un projecte de la Comissió Europea del Programa Sòcrates, anomenat Comènius II $^{9}$, acció que es basa en projectes transnacionals d'educació intercultural. Les actuacions portades a terme s'han realitzat dins de l'atenció d'alumnes immigrants procedents de països àrabs i la promoció de l'educació intercultural (Departament d'Ensenyament, 1996a).

Analitzant amb més profunditat les orientacions d'aquest programa, el curs 1999-2000, quant a intervencions i actuacions als centres veiem que:

a) Els centres on s'intervé

El PEC no intervé en totes les institucions escolars (de primària i secundària) que reben alumnat d'origen immigrant, sinó en els centres que han cursat una demanda oficial, generalment, via Inspecció, que, tenint en compte les propostes dels professionals del programa, decidirà els centres en què treballarà aquell curs. S'estableixen atencions puntuals, periòdiques $\mathrm{i}$ es deixen unes quantes hores setmanals per a d'altres tasques burocràtiques i imprevistos. Atès el gran volum de centres que opten per aquest servei, es consideren preferents els que reben per primera vegada alumnes immigrants. Per això, és habitual que els mestres del PEC no vagin cada curs als mateixos centres.

El nombre d'escoles que atén el PEC varia d'acord amb les orientacions generals que arriben del Departament. A l'inici de la seva creació, s'intentava respondre a totes les demandes, però llavors l'assistència del programa era considerada sols un "apagafocs", per això, des del curs 1998-1999, es limita a un determinat nombre de centres (tot i que n'hi ha d'altres que també seria adient anar-hi). La mitjana dels centres que es visita periòdicament és d'uns deu: al matí, cinc de periòdics i, a la tarda, cinc més de puntuals, es deixen dues tardes lliures per a noves demandes i tasques de preparació de materials. Aquests canvis responen a una nova direcció del programa:

En un primer período, el PEC centraba su actuación en la atención directa a los nuevos alumnos. Los tutores y el claustro valoraban positivamente este apoyo porque son estudiantes que aprenden deprisa, son como esponjas, pero necesitan una atención individualizada que la escuela no puede asumir [...] Después, se intentó reconvertir la intervención dando más peso al asesoramiento y a la orientación, con el objetivo de que fueran los centros quienes asumieran la nueva situación. Aunque los profesores del PEC valoran positi-

9. El Programa Sòcrates de la Unió Europea va ser establert l'any 1995 per un període de quatre anys per a la cooperació en l'àmbit de l'educació i inclou el capítol II, acció 2: Comènius, que constitueix la primera innovació de programa amb la introducció de la cooperació europea en l'ensenyament escolar. Concretament, el Comènius II cerca la promoció d'una relació tan completa com sigui possible en les activitats i en la igualtat d'oportunitats dels nens de treballadors immigrants, així com de fills de persones que exerceixen una professió itinerant, viatgers i d'ètnia gitana; bàsicament es dóna suport a les associacions entre centres, els intercanvis de professors i la formació contínua (Gomis, 1996). 
vamente el contacto directo con los estudiantes de origen inmigrante, esta labor les ocupa muchas horas y les resta tiempo para preparar programas para el profesorado y ocuparse de la coordinación, que, de hecho, son las actuaciones que sirven para difundir la interculturalidad en la escuela. Pero en la práctica, los miembros del PEC acaban prestando atención directa en muchos casos. (Crespo, 1997, p. 646)

La distribució de centres entre els professionals del PEC correspon a cada delegat territorial (o persona en qui delegui la distribució dels centres). A l'hora d'aplicar-la, s'ha de tenir en compte l'experiència prèvia o l'especialització del professional en educació infantil, primària o secundària, i el nombre de cursos que el professional atén en un mateix centre, tenint en compte els criteris de temporització.

b) Les actuacions als centres

La finalitat del PEC és col-laborar amb els centres i professors en la integració escolar d'alumnes amb risc de marginació social i/o alumnes estrangers que presentin necessitats educatives especials associades a situacions socials o culturals desfavorables, amb dificultats d'accés, permanència i promoció en el sistema educatiu (prioritzant els de primària i els que s'escolaritzen al primer cicle de secundaria obligatòria). L'actuació dels mestres i dels treballadors socials ha de permetre que aquest alumnat rebi una resposta escolar a les seves necessitats. Això implica la col-laboració amb els centres respecte al seguiment d'alumnes que puguin presentar dificultats d'escolarització en el pas de primària a secundària, l'acollida dels nouvinguts, el suport temporal directe a aquells que ho necessitin, l'ajuda en les diferents formes d'organització d'aula per atendre la diversitat, l'adaptació de materials, la proposta d'estratègies i d'activitats per fomentar la diversitat cultural al centre i uns altres temes de naturalesa semblant. L'atenció directa als centres comporta, com a mínim, vint-i-quatre hores setmanals (s'hi destinen preferentment tots els matins i tres tardes). D'altra banda, aquesta atenció demana la cooperació amb els programes i serveis educatius del Departament, així com instàncies dependents d'altres departaments. De manera especial, s'ha de preveure el treball conjunt amb els psicopedagogs adscrits als centres de secundària, amb els professionals dels Equips d'Assessorament Psicopedagògics (EAP) i els del Servei d'Ensenyament del Català (SEDEC) que intervenen en els mateixos centres, a fi de conjugar les actuacions relacionades amb els alumnes que s'han d'atendre i les mesures d'atenció a la diversitat per assolir la màxima congruència en les ofertes.

El desenvolupament d'un programa concret és acordat i signat per la direcció del centre conjuntament amb els professionals del PEC. El seu pla de treball fa referència als centres docents (pla d'acollida i escolarització, orientació i informació als centres, a les famílies i a l'alumnat) i a l'entorn social (absentisme escolar i programes de mediació). En plantejar per primera vegada actuacions en centres, el programa ho fa sempre amb caràcter transitori, $\mathrm{i}$ les activitats es concreten, per a un màxim de tres anys conse- 
cutius, en funció dels objectius consensuats. Si els factors que van ocasionar la intervenció es mantenen al final dels tres anys, cada curs es pot valorar la conveniència de continuar-ne un altre i, si escau, també es pot prorrogar l'actuació.

El PEC ha anat rebent, progressivament, més concreció pel que fa a les seves primeres orientacions i prioritats, que, darrerament (Departament d'Ensenyament, 1999), s'havien concretat en:

1. Línies prioritàries d'actuació dels mestres. Col-laborar en les actuacions relacionades amb l'acollida d'alumnes (oferir informació i orientació sobre les diferències culturals, participar en l'observació i detecció de les necessitats, facilitar criteris per a la relació amb les famílies, assegurar una bona relació amb els companys del grup classe, cooperar amb les actuacions adreçades a la prevenció de l'absentisme i assegurar el pas de primària a secundària), atendre directament els alumnes (en funció de les necessitats detectades, amb un treball de preparació previ amb el tutor i quan es consideri pertinent, individualment, en grup reduït, grup classe o altres tipus d'agrupaments), facilitar orientacions als mestres i professors sobre l'aprenentatge del català per part dels alumnes d'incorporació tardana (d'acord amb els criteris del SEDEC, sempre que no sigui possible la intervenció dels assessors corresponents), facilitar els materials didàctics adaptats a les necessitats (sense que estiguin desvinculats de les activitats de la resta del grup), col-laborar en la realització i posada en pràctica de crèdits variables de reforç (d'acord amb la comissió d'atenció a la diversitat del centre), ajudar en la gestió d'ajudes econòmiques (referents a llibres, material didàctic i menjador escolar) i fomentar l'educació intercultural en el centre (suggeriments, seguiment i revisió sistemàtica de les activitats).

2. Línies d'actuació dels treballadors socials. Atendre les famílies dels alumnes amb risc de marginació (per tal d'orientar-les en els processos de matriculació, en els tràmits corresponents, millorar la relació amb la institució), cooperar amb els centres i amb els serveis socials en l'atenció als alumnes en situació d'alt absentisme o abandó escolar (especialment en el disseny i en la realització d'accions que permetin la participació progressiva), col-laborar i vetllar per l'aplicació de programes de salut escolar (més concretament el que fa referència als alumnes i a les seves famílies a fi de millorar les condicions relatives als hàbits d'higiene, d'alimentació i d'aspectes preventius relacionats amb la salut), col-laborar i gestionar els tràmits dels ajuts econòmics (referents a llibres, material didàctic i menjador), coordinar-se amb els treballadors socials dels EAP (per tal de complementar i donar continuïtat a les intervencions derivades dels àmbits socials).

3. Respecte a la formació dels professionals, els del PEC poden participar en les activitats de formació permanent que s'ofereixen als docents de la zona, on intervenen en les mateixes condicions que la resta del professorat, tot $\mathrm{i}$ que disposen d'un pla de formació específica per assegurar el correcte desen- 
volupament de les funcions encomanades. Sobretot la intervenció a secundària no es pot fonamentar en la bona voluntat dels professionals ni en el bagatge personal i professional de cadascú. En aquest sentit, fins al curs 1998-1999 es plantejaven contradiccions (Programa d'Educació Compensatòria, 1998), com ara:

- Intervencions de persones que no necessàriament estaven acreditades per anar-hi.

- Per altra banda, aquesta actuació no anava acompanyada de cap reconeixement respecte a aspectes com ara els horaris, l'equiparació econòmica, els mèrits o d'altres.

Aquests dos fets comportaven que sovint es realitzés una feina de contingència, ja que es responia a les necessitats més imminents dels alumnes i s'hi introduien pocs elements (superficials i anecdòtics) de caràcter intercultural.

A tall de balanç, en l'esborrany sobre Educació $i$ immigració extracomunitària, del Grup FUS (1999), s'hi analitza la trajectòria d'aquest programa i es considera que hauria de consolidar-se com a referència per a la prevenció de l'exclusió social i el tractament de la diversitat cultural a l'escola. Però, per això, aquest grup creia que havia de realitzar unes modificacions:

- En primer lloc, canviar-se el nom ${ }^{10}$ per un de més complet i menys segregador, per exemple, aposten pel de Servei Educatiu per a la Igualtat d'Oportunitats i l'Educació Intercultural (SEIO).

- Consolidar el programa com a servei ${ }^{11}$ permanent, això garantiria més professionalitat i més interès per part dels professionals que hi treballessin.

- Definir i concretar les línies, les orientacions i les tasques del programa per a totes les delegacions, tot i que després podria adaptar-se a cada territori.

- Intensificar el reciclatge i els itineraris d'especialització dels professionals que hi treballen.

- Distribuir els professionals d'acord amb les necessitats i avaluar els resultats des d'òptiques diferents.

Per Carbonell (2000), aquest programa ha de reorientar la seva línia de treball i actuació a fi de consolidar-se com a marc de referència per a la prevenció de l'exclusió social i el tractament de la diversitat a les institucions escolars, i abandonar la provisionalitat i la deixadesa en què sempre ha estat immers,

10. Des del curs 1994-1995, algunes delegacions (la primera va ser Girona) han suggerit reiteradament el canvi del nom, i han aportat diferents propostes amb relació a l'educació intercultural. També el Consell Escolar de Catalunya (1997) ha manifestat la necessitat de fer-ho.

11. El fet d'estar en comissió de serveis fa que molts professionals marxin quan tenen una plaça estable i definitiva, igual que d'altres que es presenten per no fer front a situacions administratives no desitjades (per exemple, tenir la plaça definitiva lluny del seu domicili) i, consegüentment, estan poc motivats inicialment per la filosofia i direcció d'aquest programa (Fernández Enguita, 1993). 
igual que la professionalització i l'especialització de la gent que hi treballa (com hem dit, sovint més interessada en situacions administratives - no moure's d'un determinat poble, barri o ciutat- que en els objectius del programa). Aquest fet, conjuntament amb les contínues crítiques dels mateixos professionals, l'augment d'alumnat en risc de marginació social i cultural a les institucions educatives, etc., ha comportat que es creés ${ }^{12}$ el Programa d'Educació Compensatòria adscrit al Servei d'Educació Especial i Programes Educatius, amb la finalitat d'assessorar i donar suport als centres de cara a la prevenció de qualsevol forma d'exclusió social i a l'educació intercultural dels alumnes.

En un dels últims documents publicats pel Departament d'Ensenyament, s'hi cita la reorientació del programa per al proper mil.lenni:

[...] l'objectiu d'aquesta intervenció és implicar els nens petits a l'escola, normalitzar-ne l'assistència i disminuir-ne la taxa de descens, acomodant les característiques particulars de cada grup cultural. [...] L’educació compensatòria respon a la desigualtat d'oportunitats que pateixen alguns grups en el sistema educatiu a causa de diferents factors (socials, econòmics, culturals, geogràfics, ètnics...). És considerada necessària per garantir uns estàndards mínims d'educació. Consisteix a implementar accions complementàries en determinades escoles (a petició d'aquestes i amb la supervisió de la Inspecció d'Ensenyament) per reduir desigualtats, adoptar mesures preventives, cosa que fa que es duguin a terme preferiblement durant els primers anys d'escolarització. (Departament d'Ensenyament, 1999, p. 7-8)

Els equips docents dels centres en col-laboració amb els professionals del PEC van definir els procediments pel que fa a l'avaluació inicial i els criteris de selecció de l'alumnat destinatari de les actuacions educatives (Departament d'Ensenyament, 1999), que atenien l'ordre de prioritat següent:

1. Desfasament escolar significatiu i dificultats d'inserció educativa derivades d'abandó familiar o de situacions de marginació.

2. Minories ètniques o culturals en situació de desavantatge que presenten desfasament escolar significatiu (dos o més cursos de diferència entre el seu nivell curricular i el que li pertoca per edat cronològica), especialment pel que fa a:

- Alumnat gitano amb necessitats de suport derivades d'una escolarització tardana i d'absentisme escolar.

- Alumnat immigrant amb necessitats de suport derivades del coneixement del català i/o del castellà o de la incorporació tardana al nostre sistema educatiu.

- En situació de risc d'abandó del sistema educatiu, que, per les seves condicions sociofamiliars, presenta desfasaments escolars molt significatius i generalitzats (en concret, més de tres cursos de diferència).

12. Segons el Decret de reestructuració del Departament d'Ensenyament, de 27 de setembre de 2000 . 
Darrerament, el Programa d'Educació Compensatòria promovia i assessorava l'elaboració d'un pla general d'acollida destinat a les escoles que prioritzava (Alegre i Herrera, 2000): l'admissió d'alumnes de famílies acabades d'arribar, la dels alumnes d'incorporació tardana i la de les famílies nombroses. Per exemple, aquests autors descrivien la tasca realitzada a Mataró a partir de dos eixos: l'acollida i el seguiment de nens magribins. La primera tasca, l'organització de l'acollida (ensenyar-los el centre, la classe, etc.), formalment és elaborada conjuntament entre el PEC i el centre d'ensenyament corresponent; tot i que varia bastant si segueix un itinerari marcat per Ensenyament. Com a darreres novetats, si hi ha alguna dificultat d'idioma es pot recórrer al mediador (que, en realitat, sols fa de traductor per explicitar la documentació necessària per poder presentar la sol-licitud de matrícula, vegeu Llevot, 2004). També es tenen en compte aspectes relatius al tipus de religió que segueix la família, si el nen ha estat escolaritzat abans o no, etc. i el nivell de competències, que el determinarà l'Equip d'Assessorament Psicopedagògic (EAP) amb proves per conèixer el nivell d'aprenentatge. En segon lloc, el seguiment posterior consisteix a vetllar que l'alumne s'integri en les activitats ordinàries per un període d'un a dos anys. Quan hi ha casos que requereixen un seguiment més exhaustiu, ja que l'alumne experimenta un contrast cultural entre allò que va descobrint i l'oferta familiar, es poden derivar els casos als serveis socials o a unes comissions de contacte amb la família.

Una altra iniciativa que també es promovia consistia en la posada en marxa de centres comarcals de recursos pedagògics dedicats tant a la programació i a la coordinació de criteris d'actuació sobre les escoles, com en l'organització de grups de treball per elaborar materials concrets (acollida, lluita contra la xenofobia, etc.).

En aquesta línia d'atenció a la diversitat, s'endegaren els Tallers de Llengua per a la incorporació tardana a la comarca d'Osona durant el curs 1996-1997, concretat en el Projecte Anselm Turmeda. L'objectiu era proporcionar als centres docents un suport específic en relació amb la incorporació tardana d'alumnes al sistema educatiu per mitjà de tallers i cursos adreçats directament a ells, per tal que adquirissin un coneixement de la llengua pròpia de l'ensenyament fins a assolir-ne una competència lingüística suficient que els permetés comunicar-se amb l'entorn immediat i seguir els aprenentatges escolars, al mateix temps que se'ls proporcionava una aproximació a les formes de vida del país que els acull i que va ocasionar, a partir del curs 1998-1999, una nova modalitat: els tallers d'adaptació escolar i d'aprenentatges instrumentals bàsics.

Globalment, el Programa Educació per al quadrienni 2000-2004 (Departament d'Ensenyament, 2000) abastava un seguit d'accions que obeïen en la seva execució al principi d'atenció prioritària a l'alumnat amb necessitats educatives específiques derivades de situacions socioeconòmiques i culturals desfavorides. Adoptava nous conceptes dins del discurs educatiu que en substituien d'altres: el de l'equitat, que supera el de la igualtat d'oportunitats per a tothom, instituint el dret de tota persona a gaudir d'oportunitats coincidents amb les seves capacitats; el de la cohesió, que substitueix el de la tolerància, i el de la integració, que reemplaça l'actuació compensatòria. Una de les actuacions que s'havia prioritzat era el control i la disminució de l'absentisme, amb 
la col-laboració dels centres docents amb les administracions locals per assolir la seva eradicació ${ }^{13}$.

Finalment, sintetitzant l'evolució d'aquest programa cap a l'educació intercultural, seguirem els comentaris de Besalú (2002, p. 147):

El primero es el que deriva de las evaluaciones llevadas a cabo: incluso en aquellas experiencias en las que ha sido posible verificar un éxito significativo al término del programa, los efectos del mismo no se han mantenido a largo plazo. Ya sabemos que la igualdad educativa no es la vía principal ni directa hacia la igualdad social. Por tanto, para lograr este objetivo son necesarias otro tipo de medidas, que ataquen directamente a las causas de la desigualdad social. Con todo, las políticas compensatorias en el ámbito escolar, al margen de sus discutibles efectos sociales, tienen indudablemente efectos positivos a nivel personal y son una muestra de la preocupación de la sociedad para hacer efectiva la igualdad de oportunidades.

Queda clar que aquestes tímides actuacions han estat insuficients per atendre les necessitats actuals d'inclusió social i escolar, i no obrien un camí clar per fer donar un tomb a la tendència d'exclusió social que presenten alguns centres educatius, de manera que hi trobem una sèrie de punts "candents» que es detallen a continuació.

S'està produint de manera preocupant la concentració d'alumnat en risc de marginació en determinats centres públics, alguns dels quals s'han acollit a la convocatòria de l'Administració educativa com a centres d'atenció educativa preferent. Aquesta adscripció comporta una sèrie d'ajudes referents a la ràtio d'alumnes per aula, dotació de més professorat de reforç, prioritat en l'adjudicació de beques i ajudes econòmiques, etc., amb la finalitat de pal.liar d'alguna manera les necessitats dels alumnes.

Però el que no s'ha fet en aquests centres ha estat crear uns programes de formació específics per als professionals que hi treballen, ni una comissió de seguiment, ni una organització de coordinació i intercanvi entre ells, de manera que es promogués uns projectes de centre i uns projectes curriculars més eficaços, en funció de la població que han d'atendre.

Tampoc no existeix cap actuació que qüestioni la fugida de la població escolar amb més expectatives socials cap a les escoles dels barris veïns que gaudeixen de més prestigi social. D'aquesta manera, la política de concerts amb l'escola privada comporta que els centres d'atenció educativa preferent vagin disminuint la matrícula i convertint-se en centres guetitzats, mentre que els privats es van ampliant ostensiblement amb noves matriculacions i edificacions. Es dóna el cas que en el mateix moment $i$ lloc en què sobren places públiques o se’n redueixen aules, es permet que les concertades ampliïn la seva oferta d'admissió d'alumnes.

13. Cada any es publica un informe a fi de retre comptes del grau d'absentisme detectat i de les mesures adoptades per combatre'l (Departament d'Ensenyament, 2000). 
En els darrers decrets de matriculació, es proposava que a tots els centres sostinguts amb fons públics —els concertats també- es faci una reserva de quatre places per aula, que ha de ser coberta per la comissió de matriculació, per donar cabuda a aquells alumnes que presentin necessitats educatives especials o necessitats específiques en funció de la seva situació sociofamiliar.

D'aquesta manera, es pretenia pal.liar la guetització d'alguns centres i ferlos participar a tots de la realitat social que ens envolta. El resultat ha estat, però, que mentre els centres concertats reben com màxim aquests quatre alumnes, les escoles públiques de les zones més deteriorades continuen acollint, quasi exclusivament, la resta d'estudiants amb més dificultats.

Cal afegir també a aquesta situació que, en les dues dècades anteriors, malgrat algunes amenaces latents, els avenços aconseguits per a la normalització de la cultura i la llengua catalanes han estat evidents a l'escola, mitjançant l'aplicació dels programes d'immersió lingüística. No obstant això, la llengua catalana encara no ha assolit una plena ni autèntica normalització en l'actual context social, on es fa més evident encara la seva fragilitat.

\section{La transformació al Pla per a la Llengua i la Cohesió Social (LIC)}

Recollint els suggeriments fets en les propostes de millora del sistema educatiu formulades per la Conferència Nacional d'Educació 2000-2002 (2002) dins de la Secció III, d'Atenció a la Diversitat, el Departament d'Ensenyament va elaborar i va iniciar el Pla d'Actuació per a l'Alumnat de Nacionalitat Estrangera 2003-2006 (PAANE). Aquest pla atenia sobretot els aspectes relacionats amb l'aprenentatge de la llengua i no tenia en compte suficientment aspectes fonamentals de l'acollida, com ara els aspectes emocionals, convivencials, relacionals i de cohesió social que incideixen sobre tot l'alumnat. Per aquesta raó, el Departament va elaborar un nou pla — que s'emmarcarà de nou dins el Pla Interdepartamental d'Immigració- amb una visió més global de proporcionar i consolidar la llengua pròpia com a eix vertebrador d'un projecte educatiu plurilingüe i d'un model educatiu intercultural, amb la finalitat d'assolir la cohesió social, el Pla per a Llengua i la Cohesió Social.

Davant els nous reptes que planteja l'acollida i la integració de l'alumnat nouvingut al sistema educatiu català, es crea, mitjançant el decret 282/2004, dins del Departament d'Educació (abans anomenat d'Ensenyament), la Subdirecció General de Llengua i Cohesió Social, amb la voluntat de garantir la igualtat d'oportunitats per accedir a una educació de qualitat, de respectar la diversitat cultural i de consolidar la llengua catalana com a eix d'un projecte educatiu plurilingüe fonamentat en els valors de la convivència, l'equitat i la inclusió escolar i social de tot l'alumnat. La Subdirecció General disposa de dues unitats administratives: el Servei d'Ensenyament del Català (SEDEC) i el Servei d'Interculturalitat i Cohesió Social (SICS), que, de manera coordinada, impulsaran el Pla en els territoris, on es hi haurà un equip de suport i assessorament de llengua, interculturalitat i cohesió social. 
Una de les aportacions d'aquest Pla és que l'educació intercultural no s'ha de plantejar com una qüestió que només afecta aquells centres amb alumnat amb risc de marginació sociocultural, sinó que ha d'esdevenir un element fonamental del currículum de tot l'alumnat, ja que posa de manifest la necessitat de treballar per construir un model de societat obert i democràtic, respectuós amb els drets de les minories. D'acord amb això, l'objectiu general és el de potenciar i consolidar la cohesió social, l'educació intercultural i la llengua catalana en un marc plurilingüe.

A partir de dades quantitatives i qualitatives en relació amb l'ús de la llengua catalana, l'existència d'alumnat amb risc de marginació o exclusió social, la situació inicial de les condicions d'escolarització i el grau d'integració de l'alumnat nouvingut, l'assoliment de les competències, entre altres aspectes, es preveu fer el seguiment d'aquest Pla per tal de poder avaluar l'eficàcia de les accions i el grau d'assoliment dels objectius proposats. Seguiment i avaluació que anirà a càrrec del servei d'inspecció educativa.

Els indicadors d'avaluació del Pla (Departament d'Educació, 2004) s'han de basar en els punts següents — tenint en compte que cal ajustar-los i adequar-los en funció de les diferents circumstàncies socials i personals de l'alumnat, de l'etapa i del cicle escolar-: temps transcorregut entre l'arribada i l'escolarització, índex d'absentisme escolar, nivell de competència lingüística en català i en castellà, resultats de les avaluacions per àrees, resultats de les proves sobre competències bàsiques, clima relacional del centre, participació en activitats extraescolars i complementàries, nombre d'alumnes que cursen estudis postobligatoris, índex de participació dels progenitors en les activitats docents. Amb la finalitat d'avaluar l'eficàcia d'aquest Pla, l'Administració vol potenciar la realització de recerques que permetin realitzar anàlisis quantitatives i qualitatives, concretes i específiques, dels centres educatius per millorar-ne l'acció i determinar, si escau, noves actuacions.

Una de les actuacions més innovadores són els plans d'entorn com a instruments per dissenyar una acció coordinada per a tot l'alumnat, posant un èmfasi especial en els escolars nouvinguts i/o en risc de marginació sociocultural i fomentant la interculturalitat i la cohesió social.

Amb aquest objectiu, s'intenta afavorir els factors d'inclusió mitjançant les línies d'intervenció que se sintetitzen tot seguit (Departament d'Educació, 2004): garantir l'aprenentatge de la llengua catalana com a eix vertebrador dins del marc d'una societat multilingüe i l'adaptació als paràmetres culturals bàsics de la societat catalana a les famílies dels alumnes; afavorir la desconcentració d'alumnat en el procés de preinscripció i matriculació ${ }^{14}$; formar els diferents estaments de la comunitat educativa per a l'acollida, la interculturalitat i les habilitats socials; fomentar la participació de les famílies; promoure la convivència i la implicació en les activitats de lleure; adequar l'oferta a les noves necessitats i als nous interessos; promoure el diàleg entre tots i cercar actituds interculturals i ciutadanes. 


\section{A tall de reflexions obertes}

En una societat tan complexa com la nostra, podem constatar que la provisió de llocs escolars gratuïts per a tothom no garanteix prou la igualtat d'oportunitats. L'origen divers i la situació social i cultural de les famílies generen expectatives educatives molt diferenciades, fins al punt, de vegades, de no atorgar gaire importància a l'educació. No tenir present aquesta qüestió porta a un discurs formalment igualitari, però a la vegada molt segregador. Així, es creu que caldrà crear, a les àrees $\mathrm{i}$ als sectors socials més deprimits, les condicions que facin efectiva la igualtat d'oportunitats per accedir a una educació de qualitat i per a tothom.

Partint del fet que, per determinades condicions històriques i urbanístiques, en algunes àrees es concentren problemes demogràfics i dèficits econòmics i socials, l'Administració, amb el Pla que inicia, sembla que es fa conscient de la necessitat que hi hagi una atenció específica i integral que parteixi d'un plantejament global, on l'escola esdevingui una peça imprescindible per poder contribuir al benestar i a la cohesió socials.

Tot i la confiança que diposita la societat en la capacitat que té la institució escolar per educar, s'afirma que aquesta no pot assumir tots els reptes en solitari. Ens trobem davant el desafiament de construir una Catalunya socialment cohesionada, acollidora i oberta, capaç de fer prevaler la idea de ciutadania per damunt d'altres elements d'identitat. En aquest sentit, cal que el sistema educatiu disposi dels instruments i els recursos que consolidin els centres docents com a espais de convivència, amb capacitat de generar noves complicitats i de sumar allò que de positiu tenen totes les cultures, on sigui possible que alumnes de procedència social i cultural ben diversa puguin construir una nova identitat col-lectiva i compartida sense excloure ningú. Per això, els centres docents han d'assumir l'acollida i la integració d'alumnat ben divers com una tasca ordinària i elemental. Aquesta és una nova exigència educativa i social comuna a tots els països que formen part de l'Europa del benestar. Així mateix els centres han de posar en marxa estratègies pedagògiques que atenguin les necessitats específiques d'alumnat en risc de marginació sociocultural.

Catalunya, com a país europeu i mediterrani, sorgit del contacte històric de pobles ben diversos, i que té la cultura i la llengua com a signes evidents d'identitat, ha de fer front a aquest nou repte i a aquesta responsabilitat amb la confiança que li atorga la seva tradició pedagògica de qualitat i enteresa $i$ les competències que, en matèria educativa, li dóna l'Estatut d'Autonomia (Departament d'Educació, 2004). Malgrat això, l'escola no pot fer-ho tota sola, cal insistir en la necessitat de treballar en aquesta línia coordinadament amb tots els agents socials i el conjunt de la societat i de les seves institucions, per això valorem positivament la implementació, dins del Pla per a la Llengua i la Cohesió Social, dels plans d'entorn com una xarxa de suport a la comunitat educativa, iniciativa que s'ha dut a terme a partir del març del 2005 i que es defineix des d'inspecció com: «[...] la implicació i coresponsabilització del conjunt d'agents i serveis educatius per tal de treballar en la línia d'una Catalunya cohesionada i oberta, democràtica, basada en la convivència i el respecte per la diversitat». 


\section{Referències bibliogràfiques}

Alegre, M. A.; Herrera, D. (2000). Escola, oci i joves d'origen magribi: El sentit de la inserció social de les segones generacions de famílies immigrades. El cas de Mataró. Barcelona: Diputació de Barcelona. (Materials de Joventut, 14).

Benestar Social (1994). Pla Interdepartamental d'Immigració. Barcelona: Departament de Benestar Social. Generalitat de Catalunya.

BERNSTEIN, B. (1971). «Education cannot compensate for society», a: Cosin, B. R. i altres. School and Society. Londres: Routdledge \& Open University, p. 64-70.

BesAlú, X. (2002). Diversidad cultural y educación. Madrid: Síntesis.

CARBONELL, F. (1997). Immigrants estrangers a l'escola: Desigualtat social $i$ diversitat cultural en l'educació. Barcelona: Fundació Serveis de Cultura Popular/Editorial Altafulla.

- (2000). Educació i immigració: Els reptes educatius de la diversitat cultural i l'exclusió social. Barcelona: Fundació Jaume Bofill/Mediterrània. (Col-lecció Polítiques, 27).

Centro de Investigación y Documentación Educativa (CIDE) (1992). El sistema educativo español. Madrid: MEC.

CONFERÈNCIA NACIONAL D'EDUCACIÓ (2002). Debat sobre el sistema educatiu català: Conclusions i propostes. Barcelona: Publicacions del Departament d'Ensenyament de la Generalitat de Catalunya.

COnSEll Escolar de CaTAlunya (1997). La diversitat a l'escola: Jornada de reflexió. Tortosa: Consell Escolar de Catalunya. Generalitat de Catalunya.

CREsPo, R. (1997). "Inmigración y escuela», a: II Informe sobre Inmigración y Trabajo Social. Barcelona: Diputació de Barcelona, p. 625-663.

DePARTAMENT D'ENSENYAMENT (1988). Instruccions del Programa de Marginats Socials. Barcelona: Generalitat de Catalunya.

- (1996a). Educació Intercultural: Orientacions per al desplegament del currículum. Barcelona: Generalitat de Catalunya.

- (1996b). 10 anys de programes educatius. Barcelona: Generalitat de Catalunya.

- (1999). Normativa: Full de disposicions i actes administratius. Barcelona: Generalitat de Catalunya.

- (2000). Educació 2000-2004. Barcelona: Generalitat de Catalunya.

Departament d'Educació (2004). Pla per a la Llengua i la Cohesió Social. Barcelona: Generalitat de Catalunya.

FERnÁNDEZ Enguita, M. (1993). «Redes económicas y desigualdades sociales». Revista Española de Investigaciones Sociológicas, núm. 37. Bellaterra: Publicacions de la Universitat Autònoma de Barcelona, p. 41-79.

Gomis, P. L. (1996). Guía práctica del Programa Sócrates 1995-2000. Madrid: CECE/CITE.

GRUP FUS (1999). Educació i immigració extracomunitària. Barcelona: Grup FUS/Fundació Serveis de Cultura Popular.

Jordán, J. A. (1992). L'educació multicultural. Barcelona: CEAC (XIII Premi Pallach d'Educació).

LlEVOT, N. (2004). Els mediadors interculturals a les institucions educatives de Catalunya. Lleida: Pagès.

Montano, F.; CASTElla, E.; PÉrEZ, P. (1992). «El Programa d'Educació Compensatòria i les minories ètniques», a: PUIG, G. (coord.). Recerca i educació interculturals. Barcelona: La Llar del Llibre, p. 203-215. 
Muñoz SEDANO, A. (1989). La escolarización de los niños gitanos e itinerantes en España. Madrid: Informe ante la Comisión de las Comunidades Europeas.

PALAUDÀRIAS, J. M. (1998). Educació $i$ integració en el cas de la comunitat marroquina a Girona: Una anàlisi entre el país d'origen i el país d'assentament. Girona: Departament de Pedagogia. Facultat de Ciències de l'Educació.

Programa d'Educació Compensatòria Tarragona/Lleida (1994). Minories ètniques i escola. Espluga de Francolí: PEC (Document intern).

Programa d'EDUCACIÓ COMPENSATORIA (1998). Memòria de final de curs 1997/1998. Lleida: PEC.

SAMPer, L.; Llevot, N.; Garreta, J.; Chastenay, M. H. (2002). «Éducation et ethnicité: le cas catalan", a: MC ANDREW, M.; GAGNON, F. Relations ethniques et éducation dans les sociétés divisées (Québec, Irlande du Nord, Catalogne et Belgique). París/Montreal: L'Harmattan, p. 127-147.

SeCretariado Nacional Gitano (1982). Escuela puente para niños gitanos. Madrid: Instituto de Sociología Aplicada. 